\title{
Balkanologie
}

Balkanologie Revue d'études pluridisciplinaires

Vol. III, n 1 | 1999

Volume III Numéro 1

\section{Qosja (Rexhep), La question albanaise}

Paris : Fayard, 1995, 326 p., chronologie, bibliographie, cartes, index.

\section{Michel Roux}

\section{CpenEdition}

\section{Journals}

Édition électronique

URL : http://journals.openedition.org/balkanologie/293

DOI : 10.4000/balkanologie.293

ISSN : 1965-0582

Éditeur

Association française d'études sur les Balkans (Afebalk)

\section{Édition imprimée}

Date de publication : 1 juillet 1999

ISSN : 1279-7952

\section{Référence électronique}

Michel Roux, "Qosja (Rexhep), La question albanaise », Balkanologie [En ligne], Vol. III, n 1 | 1999, mis en ligne le 03 juin 2008, consulté le 17 décembre 2020. URL : http://journals.openedition.org/ balkanologie/293 ; DOI : https://doi.org/10.4000/balkanologie.293

Ce document a été généré automatiquement le 17 décembre 2020.

(c) Tous droits réservés 


\title{
Qosja (Rexhep), La question albanaise
}

Paris : Fayard, 1995, 326 p., chronologie, bibliographie, cartes, index.

\author{
Michel Roux
}

\section{RÉFÉRENCE}

Qosja (Rexhep), La question albanaise, Paris : Fayard, 1995, 326 p., chronologie,

bibliographie, cartes, index.

$1 \mathrm{Au}$ moment où les armes se taisaient en Bosnie est paru un ouvrage rappelant opportunément qu'il subsiste dans les Balkans une question nationale sans solution, et qui en propose une. Organisé en dix chapitres chronologiques qui resituent la question albanaise dans une perspective historique en partant de la Renaissance nationale de la seconde moitié du XIXème s., il comporte deux temps forts.

2 Le premier (chapitre IV) traite de la Conférence des ambassadeurs de Londres, qui, réglant en 1913 les problèmes politiques nés des guerres balkaniques, donna à la question albanaise une configuration territoriale presque inchangée depuis. Les Albanais étaient depuis des siècles sujets ottomans. Même s'ils l'acceptaient mal, cette situation leur donnait au moins l'unité territoriale. Mais leurs aspirations tardives à la formation d'un État-nation furent contrariées par les ambitions des peuples balkaniques qui les avaient précédés dans cette voie: si la Conférence reconnut l'indépendance de l'Albanie, celle-ci comprenait moins de la moitié de l'aire de peuplement albanais et de sa population. Le reste fut attribué à la Grèce et surtout à la Serbie et au Monténégro, qui devaient entrer en 1918 dans la composition de la Yougoslavie. Le destin de la nation albanaise au $\mathrm{XX}^{\mathrm{ème}} \mathrm{s}$. fut donc de subir un morcellement politique, assorti, surtout en Yougoslavie, d'une politique généralement répressive et de tentatives de nettoyage ethnique, la seule embellie véritable se situant au Kosovo entre 1968 et 1981 (chap. V à VII). Cette situation de partition, de répression subie et de frustration est une cause majeure du retard culturel et économique des régions de peuplement albanais ainsi que d'errements politiques comme l'acceptation du fascisme en 1941 ou le stalinisme renforcé de l'Albanie d'Enver Hoxha. 
3 Le second temps fort de l'ouvrage, qui correspond aux trois derniers chapitres, porte sur l'analyse de la question albanaise dans le contexte de la décomposition de la Yougoslavie. L'effondrement de l'ordre communiste, dont celle-ci n'est qu'un des aspects, a engendré une situation momentanément propice à la création ou à l'achèvement d'États-nations aux dépens des trois "fédérations impériales communistes" qu'étaient l'URSS, la Tchécoslovaquie et la Yougoslavie. Les autres peuples concernés ont déjà largement atteint leurs buts. Il appartient aux grandes puissances d'aider les Albanais à réaliser eux aussi leur unité nationale en défaisant l'ordre territorial injuste qu'elles ont elles-mêmes instauré en 1913. Car forcer la Serbie à rendre au Kosovo son autonomie d'avant 1989 reviendrait à solder, comme d'habitude, une crise balkanique au détriment des Albanais, et ne saurait fonder une stabilité régionale durable. Un État qui rassemblerait toutes les régions à majorité albanaise des Balkans couvrirait, selon Qosja, 50 à $55000 \mathrm{~km}^{2}$ pour 7 millions d'habitants (p. 269), soit proportionnellement moins que l'espace dont disposent les Serbes ou les Grecs; ce ne serait que "l'Albanie naturelle" et non une "Grande Albanie", notion applicable aux seuls États dont le territoire s'étend à des espaces où une autre nation est majoritaire.

4 Le livre de Rexhep Qosja appartient à la catégorie des essais historiques et géopolitiques qu'inspirent les situations de crise, et dont le début du $\mathrm{XX}^{\text {ème }} \mathrm{s}$. avait connu, sur des sujets analogues, une riche floraison. Il est animé d'une conviction et parfois d'une véhémence que le traducteur, Christian Gut, a parfaitement su rendre. L'ex-Yougoslavie y est qualifiée de "galimatias ethnique et culturel" (p. 214) et d'“État policier baroque" (p. 185) voué à la destruction dès son premier jour. On doit le prendre, non comme un travail scientifique distancié et féru d'objectivité - ce sont là, d'ailleurs, des exigences difficiles à tenir intégralement en de pareilles matières, même par des temps plus calmes - mais comme une œuvre engagée, un plaidoyer. Comme tel, il simplifie l'histoire, gommant ce qui différencie ou oppose les Albanais entre eux, affirmant hardiment qu'ils n'ont "jamais pactisé avec le pouvoir turc" (p. 103). De même, il surestime largement le nombre des Albanais en ex-Yougoslavie lorsqu'il l'évalue à trois millions. Il s'agit pour lui de montrer que la question albanaise n'est pas une question (interne) de minorité nationale propre à la nouvelle Yougoslavie (Serbie et Monténégro) ou à la Macédoine, mais, à l'échelle des Balkans, le problème d'une nation fragmentée, dont la moitié seulement habite l'État éponyme. Il s'agit aussi d'affirmer que les Albanais, en passe de rattraper numériquement les Serbes, les Grecs ou les Bulgares, sont l'une des nations principales de la péninsule.

5 La position de R. Qosja, qui fait apparaître la non résolution de la question albanaise comme une malheureuse et dangereuse exception dans un processus général d'achèvement d'États-nations, repose sur une analyse critique de la manière dont la communauté internationale gère ce processus. Selon lui, l'erreur était de favoriser une partition de l'ancienne Yougoslavie selon les frontières de ses républiques, solution de facilité apparente qui, en fait, d'un côté lèse totalement les seuls Albanais et de l'autre débouche sur le partage sauvage de la Bosnie. Il aurait fallu, au contraire, se fonder sur le droit des peuples à l'autodétermination et établir de nouvelles frontières. La solution qu'il préconise, le rattachement du Kosovo à l'Albanie, se justifie à ses yeux par le fait que les peuples voisins ont déjà réalisé leur propre État ou sont en passe de le faire (le destin de la Bosnie est, estime-il, le partage). Or, cette solution n'est pas celle que recherchent les dirigeants politiques albanais du Kosovo et leur chef Ibrahim Rugova : 
ceux-ci, dans une démarche identique à celle des Républiques qui se sont séparées de l'ancienne Yougoslavie, revendiquent pour le Kosovo le statut d'État indépendant. Qosja, universitaire kosovar, critique littéraire et romancier connu, lui-même politiquement engagé, estime que cela ne suffit pas, mais ne leur adresse ici aucune critique élaborée. Plus étonnante est l'absence totale d'analyse de la position officielle de Tirana, qui ne revendique pas l'union avec le Kosovo, n'en soutient pas non plus la revendication d'indépendance et a dans cette affaire une position très en retrait.

6 La présentation matérielle du texte souffre peu de remarques. Les coquilles sont rares, hormis dans la transcription de mots serbes. On se demande toutefois pourquoi le nom de l'écrivain albanais Pashko Vasa est orthographié Pasco Wassa (p. 20 et 23). Il aurait été opportun d'indiquer, outre l'édition croate de l'ouvrage fondamental d'Ivo Banac, l'édition de langue anglaise, accessible à un plus grand nombre de lecteurs (The National Question in Yugoslavia. Origins, History, Politics, Ithaca, Cornell University Press, 1984). L'appellation de kominformistes, pour désigner les partisans de la politique de l'URSS, aurait dû être préférée à celle d'inform-buroïstes (p. 207), insolite en français. Seule la cartographie a de quoi faire rugir, surtout si on la compare aux cartes souvent remarquables techniquement qui accompagnaient les essais politiques sur les Balkans parus il y a près d'un siècle. Il s'agit ici d'un genre qui se répand fâcheusement, la CMO, cartographie massacrée par ordinateur: vite fait, mal fait, non vérifié. Istanbul a abandonné le Bosphore et le mot Albanie est à l'emplacement de la Macédoine (p. 299). Mal orthographiés sont Kolašin (p. 301), Ferizaj, Vuçitërnë, Prishtinë, Rožaje, Kičevo et Preševo (p. 306); d'ailleurs les deux dernières devraient être notées Kërçovë et Preshevë puisque l'ouvrage met en graphie albanaise les noms des lieux où les Albanais sont majoritaires, et cela vaut aussi pour Tetovo, Debar et Gnjilane (Tetovë, Dibër, Gjilan). Enfin, la dernière carte, p. 307, consacrée à la proportion d'Albanais par commune, est rendue incompréhensible par la permutation de trois types de hachures : il faut lire 50 à $80 \%$ au lieu de 10 à 30,30 à 50 au lieu de 50 à 80 , enfin 10 à 30 au lieu de 30 à $50 .$. faute de quoi on pourrait croire, par exemple, que Skopje est à majorité albanaise, ce que personne ne prétend. Encore la source, non indiquée, n'est-elle pas le recensement yougoslave de 1991, mais une estimation de source albanaise qui majore la proportion d'Albanais dans certaines communes. Cette même carte figure - sans les erreurs ci-dessus - dans d'autres publications, comme la revue Kosova, nº 1, Tirana, 1993.

7 Attachées à résoudre les conflits de Croatie et de Bosnie-Herzégovine, les organisations internationales et les puissances ont tardé à accorder à la question albanaise une attention suffisante. Surtout, elles ne paraissent pas l'envisager dans sa globalité. L'argumentaire que Qosja verse au dossier, plaidoyer fondé sur l'idée d'une injustice historique faite aux Albanais et de leur droit à en obtenir réparation, permet d'accéder à cette dimension globale. Mais il est, comme tant d'autres essais balkaniques récents, tout entier situé dans la perspective de l'ethno-nationalisme. Une perspective dont la résolution de la présente crise balkanique implique le dépassement. 